\title{
Semantic features and communicability of words of different form-classes
}

KATE LOEWENTHAL, Department of Social Science and Humanities, The City University, London E.C.1, England

This experiment attempted to externalize the dictionary entries of words of different form-classes by getting $S$ to communicate the words to another $S$ by writing short clues. Elementary semantic properties of words were missing from the protocols; only distinguishers were being given. Low-frequency words were less successfully communicated than high-frequency words, and adverbs were less well communicated than other parts of speech. The ease with which different form-classes of words could be defined varied: adverbs were harder than other form-classes, requiring more clues; and low-frequency words were harder than high-frequency words.

Psychologists' approaches to the study of meaning have been varied: Razran (1939), Osgood, Suci, \& Tannenbaum (1957), Noble (1952), and Deese (1965) represent some extremes of approach. The approach on which this experiment is based comes from Katz \& Fodor (1963), whose theory suggests that each lexical item is specified by an entry consisting of syntactic and semantic markers, and distinguishers reflecting what is idiosyncratic about the meaning of a lexical item. Although the theory was not put forward as a psychological one, it has been popular among psycholinguists (e.g., Brown \& McNeill, 1966; Marshall \& Newcombe, 1966: Miller, 1968). Miller showed that nouns are grouped together in ways that might be accounted for by a dictionary-entry theory, although the dictionary entries for the words used in Miller's study are left unspecified.

In the present experiment it was assumed that people might have access to at least some of the features of the words they know. S's task was to write clues of a single word or short phrase about a word until another $S$ was able to guess the word. In this way it was hoped to externalize the dictjonary entries of words. A second aim of the experiment was io see whether words of different form-classes and different frequency of occurrence varied with respect to the ease with which they can be communicated and defined.

\section{SUBJECTS}

Subjects were 20 social science, engineering, and physics undergraduates in the City University, London: 4 were female and 16 were male. They were grouped into 10 pairs.

\section{MATERIALS}

A pool of 32 words was used: 8 nouns, 8 adjectives, 8 verbs, and 8 adverbs. Half the words of each form-class occurred at a frequency of at least once but less than twice per million (Thorndike \& Lorge, 1944), and the other words were AA words. Table 1 shows the words used.

\section{PROCEDURE}

Each pair of Ss had an envelope containing eight words typed on slips of card-one high-frequency and one low-frequency word of each form-class drawn at random from the pool. One member of each pair of Ss was designated the "describer," the other the "guesser." The describer was instructed to take one word at a time and to communicate it, using clues consisting of single words or very short phrases. Guesses could be made about the word at any time. All this activity was written and no speaking was allowed. Ss were allowed to give in before a word had been guessed, after consulting $E$, providing they had made a reasonable attempt and had really got stuck.

\section{RESULTS}

Quantitative Results

Table 1 summarizes the quantitative results. The likelihood of a word being correctly communicated depends on both form-class and frequency of occurrence: AA words are communicated well, and low-frequency words are communicated badly; nouns, verbs, and adjectives are communicated well, while adverbs are communicated poorly. A Cochran Q test (Siegel, 1956) showed that variation between words of different type with respect to their being successfully communicated was highly significant $(\mathrm{Q}=24.5$, df $=7, \mathrm{p}<0.001)$. The number of clues used to describe a word is an index of difficulty in defining that word.

An analysis of variance on the number of clues given for words of different types indicated both part of speech $(F=7.3$, $\mathrm{df}=3 / 62, \mathrm{p}<.001$ ) and frequency of occurrence $(F=6.2, \mathrm{df}=1 / 62, \mathrm{p}<.025)$ to be significant. (High-frequency words had a mean of 3.00 words each, and low-frequency words a mean of 4.01 clues.) Words which were communicated successfully had a mean of 3.00 clues each, while unsuccessfully communicated words had a mean of 5.03 clues $(F=19.8$, $\mathrm{df}=1 / 62, \mathrm{p}<.001)$. Since there was great variation by form-class and frequency of occurrence with respect to likelihood of successful communication, a second analysis of variancé on number of clues was carried out, this time considering only those words which had been communicated successfully. Table 1 gives some relevant means. Form-class is a nearly significant source of variance $[F=2.60$, df $=3 / 54, p$ is just greater than .05], but no other sources of variance were significant. Thus, when a word has been communicated successfully, its form-class and frequency of occurrence are not important determinants of difficulty in defining it.

Qualitative Results

The technique used was not a great success in externalizing dictionary entries of the form suggested by Katz \& Fodor (1963).

Table 1

The Words Used in the Experiment, the Number of Words Communicated Correctly, and the Mean Number of Clues Given, Arranged by Form-Class and Frequency of Occurrence

\begin{tabular}{|c|c|c|c|c|c|c|c|c|}
\hline & \multicolumn{2}{|c|}{ Nouns } & \multicolumn{2}{|c|}{ Adjectives } & \multicolumn{2}{|c|}{ Verbs } & \multicolumn{2}{|c|}{ Adverbs } \\
\hline & $\begin{array}{l}\text { High } \\
\text { Frequency } \\
\text { (H) }\end{array}$ & $\begin{array}{c}\text { Low } \\
\text { Frequency } \\
\text { (L) }\end{array}$ & $\mathbf{H}$ & $\mathbf{L}$ & $\mathbf{H}$ & $\mathbf{L}$ & $\mathbf{H}$ & $\mathbf{L}$ \\
\hline $\begin{array}{l}\text { Words } \\
\text { Used }\end{array}$ & $\begin{array}{l}\text { Night } \\
\text { Difference } \\
\text { Youth } \\
\text { World }\end{array}$ & $\begin{array}{l}\text { Docility } \\
\text { Leniency } \\
\text { Typhus } \\
\text { Siding }\end{array}$ & $\begin{array}{l}\text { Nice } \\
\text { Simple } \\
\text { Wrong } \\
\text { Different }\end{array}$ & $\begin{array}{l}\text { Salty } \\
\text { Guttural } \\
\text { Resonant } \\
\text { Erratic }\end{array}$ & $\begin{array}{l}\text { Thank } \\
\text { Write } \\
\text { Take } \\
\text { Understand }\end{array}$ & $\begin{array}{l}\text { Narrate } \\
\text { Haggle } \\
\text { Revere } \\
\text { Evaluate }\end{array}$ & $\begin{array}{l}\text { Next } \\
\text { Since } \\
\text { Yet } \\
\text { Usually }\end{array}$ & $\begin{array}{l}\text { Grandly } \\
\text { Supremely } \\
\text { Quaintly } \\
\text { Emotionally }\end{array}$ \\
\hline \multicolumn{9}{|c|}{$\begin{array}{l}\text { Number } \\
\text { Communicated }\end{array}$} \\
\hline $\begin{array}{l}\text { Correctly } \\
\text { (Max. } 10\end{array}$ & $\begin{array}{ll}y & 10 \\
0) & \end{array}$ & 8 & 10 & 6 & 10 & 8 & 6 & 2 \\
\hline $\begin{array}{l}\text { Mean } \\
\text { Number } \\
\text { of Clues }\end{array}$ & 3.0 & 4.8 & 1.4 & $2.3^{3.2}$ & 2.5 & 3.4 & 5.15 & 5.0 \\
\hline $\begin{array}{l}\text { Mean Nu } \\
\text { of Clues } \\
\text { Correctly } \\
\text { Commun } \\
\text { Words O }\end{array}$ & $\begin{array}{l}1 \text { mber } \\
\text { for } 3.0 \\
\text { y } \\
\text { nicated } \\
\text { nly }\end{array}$ & 3.9 & 1.4 & $2.0^{3.0}$ & $\begin{array}{l}2.5 \\
\end{array}$ & 3.1 & 4.5 & 4.5 \\
\hline
\end{tabular}


Syntactic features were seldom mentioned (and then sometimes wrongly) and elementary semantic features-such as (animate), (evaluative)-are also lacking in the protocols. Ss seem to have been trying to give synonyms for words, and so the protocols contain only distinguishers, which presumably have a maximal number of semantic markers in common with the target words. Sometimes phonetic or "syntagmatic" clues are given. An illustrative selection of protocols follows, with the target word in capitals, and guesses in brackets:

YOUTH: boy (girl), young (infant), -hostel (youth).

DOCILITY: quiet, still (dead), used of animals, tranquil (placid, calm), try again (peaceful), especially normally aggressive animals, female deer sound (doe), second part like smile (docile), same part of speech as tranquility (docility).

WRONG: not right (wrong).

ERRATIC: sudden actions (impulses), jerky, not uniform (irregular), like Joe, may be neurotic. (Not guessed.)

TAKE: steal (rob, pilfer, remove), -away (take).

REVERE: look up to (admire), respect (appreciate), as in a vicar (reverend), verb (revere).

NEXT: one after (next).

SUPREMELY: uppermost (top), best (elite), well done, very well done (excellent), his-highness (royal), pinnacle (peak), extremely. (Not guessed.)

\section{DISCUSSION}

The communication technique used in this experiment must be considered a failu re - as a method of externalizing dictionary entries.

The variation between words of different form-class with respect to communicability and the ease with which they can be defined may be compared with other observations. Miller (1968) finds that parts of speech other than nouns are not grouped together in ways that a dictionary-entry theory might account for. Fillenbaum (1964) showed that words of ambiguous form-class were semantically satiated and more rapidly when they functioned as adverbs than when they functioned as nouns, the former, it was argued, being more dependent on context for their meaning. Deese (1962) has shown that words of different form-class vary in the likelihood of eliciting paradigmatic word associations. Nouns are most likely and adverbs least likely to elicit paradigmatic associations, with verbs and adjectives intermediate; also, high-frequency adjectives are more likely than low-frequency adjectives to elicit paradigmatic associations. Deese argues that these findings can be explained by a hypothesis that the types of words most likely to elicit paradigmatic associations are those least dependent on their verbal contexts. Nouns seem to appear first in speech development. The author's daughter, for example, at the age of 24 months had a vocabulary of probably well over 100 names-for-things before the first handful of adjectives and names-for-actions appeared; no adverbs had appeared at this time or in the ensuing 3 months. Nouns may be more resistant to aphasic impairment than other form-classes: a paralexic studied by Marshall \& Newcombe (1966) had less difficulty in encoding correctly the form-class of nouns than of verbs, with adjectives intermediate

The evidence suggests that nouns are relatively context-independent, are acquired earliest, and are lost least readily; adverbs are least robust and most context-dependent adjectives and verbs are intermediate. In view of this, the findings of the present experiment in which adverbs and low-frequency words are difficult to define and to communicate supports the idea that the meanings, whatever their nature, of certain words do not perhaps exist as separately stored entities for each lexical item.

\section{REFERENCES}

BROWN, R., \& MCNEILL, D. The tip-of-the-tongue phenomenon. Journal of Verbal Learning \& Verbal Behavior, 1966, 5, 325-337.
Dl:IESE, J. fiorm-class and the determinamts of asiociation. Journal of Verbal Learning \& Verbal Behavior. 1962. 1. 79-84.

DEESE, J. The stricture of associatire meaning. Baltinore: Johns Hopkins Press. 1965.

FILLENBAUM. S. A turther study of grammatical class as a variable in verbal satiation. Language \& Speech, 1964, 7, 233-237.

KATZ, J. J., \& FODOR, J. A. The structure of a semantic theory. Language, 1963, 39, 170-210.

MARSHALL, J. C., \& NEWCOMBE, IF. Syntactic and semantic errors in paralexia. Neuropsychologia, 1966, 4, 169.

MILLER, G. A. Algebraic models in psycholinguistics (summarized by R. Goodwin). In C. Vlek (Ed.), Algebraic models in psychology. Proceedings of the NUFFIC International Summer Session in Science, The Hague. August 1968. Pp. 161-224.

NOBLE, C. E. An analysis of meaning. Psychological Review, 1952,59,421-430.

OSGOOD, C. E., SUCI, G., \& TANNENBAUM,P. The measurement of meaning. Urbana. Ill. Univeristy of Illinois Press. 1957.

RAZRAN, G. H. A quantitative study of meaning by a conditioned salivary technique (semantic conditioning). Science, 1939, 90, 89-90.

SIEGEL, S. Nonparametric statistics. New York: McGraw-Hill, 1956.

THORNDIKE, E. 1., \& LORGE, I. The teacher's word book of 30.000 words. New York: Columbia University Press. 1944.

\section{NOTE}

1. Thanks are due to Roger Goodwin, Department of Psychology, University College. London, for helpful discussions of this experiment.

\section{Relation of mental ability to preference for varying rates of auditory stimulation 1}

JAMES E. LERI and NORMAN J. LESSWING, Allegheny College, Meadville, Pa. 16335, and MERRILL F. ELIAS, ${ }^{2}$ Duke University, Center for the Study of Aging and Human Development, Durham, N.C. 27706

Preferences for varying rates of auditory stimulation were compared for three groups: (a)older $S s$ of average $I Q$, (b) younger $S$ s of average $I Q$, and (c) older retarded Ss. All possible pairs of eight different auditory rates, consisting of differing numbers of tones per $10-\mathrm{sec}$ period, were presented. Younger $S s$ of average $I Q$ showed a greater preference for the highest rates of stimulation than the older Ss. Preferences of older retardates were more similar to younger Ss.

Knowledge of the relationship between mental ability (MA) and preference for varying rates of stimulation may be important for an understanding of the role of motivational or activation mechanisms in the retardate's adjustment to his environment. There have been few, if any, studies of this relationship, but Boesch, Baltes, \& Schmidt (1968) have reported marked differences in preference for different rates of auditory stimulation among Ss of different ages. The relationship between number of tones per 10-sec period (rate of stimulation) and preference was essentially curvilinear for Ss from 12 to 20 years. They showed an increased preferenec 